\title{
Highlighting marital HIV risk and promoting premarital VCT in Nyanza Province, Kenya
}

Ben Ochieng

Annabel Erulkar

Population Council

Follow this and additional works at: https://knowledgecommons.popcouncil.org/departments_sbsr-rh

Part of the International Public Health Commons, Public Health Education and Promotion Commons, Social and Behavioral Sciences Commons, and the Women's Health Commons How does access to this work benefit you? Let us know!

\section{Recommended Citation}

Ochieng, Ben and Annabel Erulkar. 2008. "Highlighting marital HIV risk and promoting premarital VCT in Nyanza Province, Kenya," FRONTIERS Final Report. Washington, DC: Population Council. 


\title{
Highlighting Marital HIV Risk and Promoting Premarital VCT in Nyanza Province, Kenya
}

\author{
Ben Ochieng \\ Annabel S. Erulkar
}

2008

This publication is made possible by the generous support of the American people through the

President's Emergency Plan for AIDS Relief (PEPFAR) and the United States Agency for International Development (USAID) under the terms of Cooperative Agreement No. HRN-A-00-

98-00012-00. The contents are the responsibility of the FRONTIERS Program and do not necessarily reflect the views of USAID or the United States Government. 
(C) 2008 The Population Council, Inc.

Suggested citation: Ochieng, Ben and Annabel S. Erulkar. 2008. "Highlighting marital HIV risk and promoting premarital VCT in Nyanza Province, Kenya," FRONTIERS Final Report. Washington, DC: Population Council.

Any part of this publication may be reproduced without permission for limited distribution provided it is distributed without charge and the Population Council is acknowledged as the source. The Population Council would appreciate receiving a copy of any materials in which the text is used. 


\section{CONTENTS}

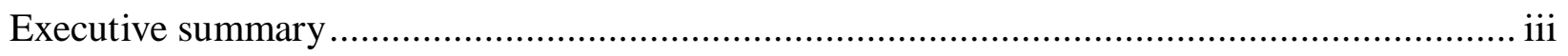

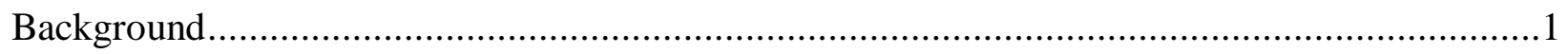

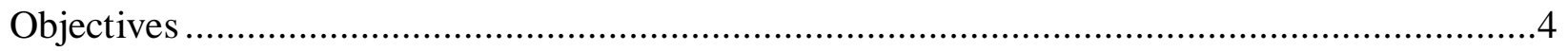

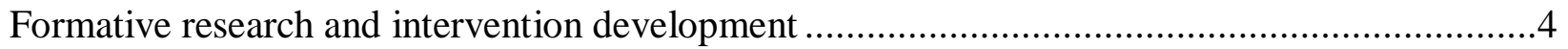

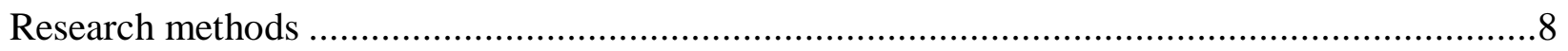

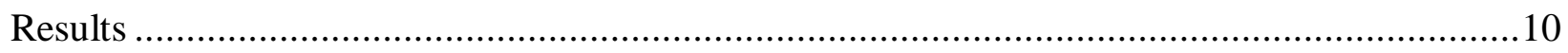

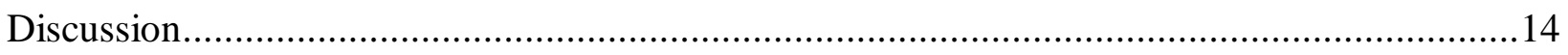

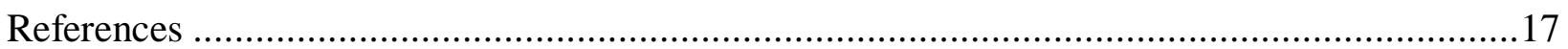




\section{EXECUTIVE SUMMARY}

Married adolescent girls form a large segment of Kenyan youth, yet they are largely overlooked by researchers and programmers, as many programs focus on the prevention of STI/HIV and unwanted pregnancies for unmarried youth. There is the widespread perception that marriage is protective against HIV, yet evidence is increasing that girls who are married are much more likely to be infected with HIV than unmarried sexually active girls. An HIV prevalence study in Kisumu, Kenya found that married girls age 15-19 had higher rates of HIV infection when compared to unmarried girls (Glynn et al, 2001).

"Highlighting Marital HIV Risk and Promoting Premarital VCT in Nyanza, Kenya" is a project of the Population Council, in collaboration with PATH and Kendu Adventist Hospital. Its specific objectives are: 1) to design and implement educational strategies to raise awareness of the risks of HIV and early marriage; 2) to promote voluntary counseling and testing for couples; and 3) to support and empower newly married girls through community-based clubs. The program was implemented in Rachuonyo and Homa Bay Districts in Nyanza Province, Kenya. The strategies to address HIV risk among married adolescent girls included: an education campaign to sensitize communities, families and young people that marriage is not protective of HIV; promotion of premarital VCT services for young couples including referral and linkage with existing services and subsidies for associated costs; and support groups for married girls. The specific achievements over two years of the intervention included:

Magnet Theatre: Fourteen theatre groups facilitated Magnet Theatre activities reaching over 20,500 males and 17,300 females, through 47,260 contacts. Messages conveyed during performances related to the HIV risk associated with marriage, fidelity, and the importance of premarital/couples VCT.

Radio: Radio spots were aired on Radio Ramogi and Lake Victoria FM, with a combined reach of between 300,000 and 500,000 people. Seven radio spots went on the air during hours that many community members listened to the radio.

Advocacy by religious leaders: Religious leaders advocated against early marriage and encouraged community members to attend VCT. They made over 1,150 referrals for VCT, and reached over 17,400 community members with messages on marital HIV risk.

Mentoring: Kendu Adventist Hospital supports mentors to mobilize and support married adolescent girls. Mentors conducted meetings that discussed HIV reaching over 7,600 married girls, STIs reaching over 5,300 married girls, VCT reaching over 6,800 girls and ARV reaching over 2,500 girls.

VCT: VCT services were designed to address barriers to VCT use, including the costs of travel to the VCT sites. A coupon system was used to encourage community members to visit VCT sites in order to know their HIV status.

Programmatic implications: This project underscored the special circumstances of married adolescents in Nyanza, a group for which there is no specialized programming. Many young women in Homa Bay described having been victims of sexual violence, making them vulnerable to HIV infection. Mechanisms to support projects for married adolescents, including access to mentors and other types of social support, need to be established. 


\section{BACKGROUND}

In recent years, there has been increased public health attention to adolescents in developing countries, especially in response to their sheer numbers, their reproductive health problems, and, most recently, the rates of HIV infection among this group (McCauley et al, 1995). However, the increased attention to adolescent research and programs has been focused almost exclusively on the unmarried, with little or no attention paid to young people who are married during their adolescent years (Mensch et al, 1998). This lack of attention has resulted, in part, because once young people are married, they enter the social category of adults, no matter their age. In marriage, girls are presumed to carry the same status and responsibilities as adult married women, an assumption that may be false. They are also presumed to have the same service needs as adult women and to be reached by adult programs. Evidence is emerging that this may not be the case (Diop and N'Dione, 2002). Married adolescents are largely invisible, overlooked by both research and programs. At the same time, the transition to marriage is a time when girls are likely to be extremely vulnerable and in need of considerable support. Emerging evidence of HIV infection among adolescent girls in sub-Saharan Africa, especially those who are married, underscores this vulnerability.

The category, married adolescent, is largely a phenomenon of girls, not boys (Mensch, Bruce and Greene, 1998, Singh et al, 2000). Marriage is a critical and pivotal experience in the adolescence of the majority of girls in sub-Saharan Africa, most of who marry before age 20 (Bledsoe and Cohen, 1993). In a review of DHS data, the median age at first marriage for girls is 19 or below in all countries in sub-Saharan Africa except Botswana, Burundi, and Namibia (Singh and Samara, 1996). While adolescent program planners tend to focus on premarital sexual activity, most girls' sexual activity occurs within marriage, as do births to adolescent girls (Singh et al, 2000, FOCUS, 1999). In Kenya, 51 percent of sexually active girls aged 15 to 19 are married (Population Council 2001, NCPD, 1998).

Married adolescents come from poorer families and have lower levels of education compared to girls who marry after adolescence (Bledsoe and Cohen, 1993, AGI, 1998, Mensch, Bruce and Greene, 1998). In addition, married girls tend to have larger age differences with their spouses often of considerable magnitude - compared to girls marrying later. While large spousal age differences are common in sub-Saharan Africa, at the extreme, they are likely to result in girls having diminished power in decision-making and are often reflective of the low status of women (AGI, 1998).

Most of the research on married adolescents has focused on the timing of marriage and childbearing. However, marriage has a significant impact on the quality of a girl's life, shifting her focus increasingly to family life and motherhood, rather than exploration of the work world or continuation of education (Mensch, Bruce and Greene, 1998, Singh and Samara, 1996). Marriage confers upon girls a new and different set of expectations, pressures and risks. Yet little research has been done to understand the new worlds of married girls, including the context of married life, how they feel about it, and how marriage shapes risk behavior, including the risk of HIV/AIDS. 


\section{Marriage in Kenya ${ }^{1}$}

Kenya is a signatory to the Convention on the Rights of the Child that defines children as those below age 18 and considers child marriage a human rights violation. In Kenya, the age at which one can legally marry is age 18 for both girls and boys. Overall, five percent of Kenyan girls are married by age 15 , and 25 percent are married by age 18 . In comparison, few boys are married during adolescence, with only three percent of boys married by age 18 .

Many girls do not choose their husband but have him chosen for them. Among married girls aged 15 to 24, 12 percent of urban girls and 19 percent of rural girls had marriages arranged for them. Moreover, there is a strong relationship between age at marriage and the likelihood that the marriage was arranged. Among Kenyan girls married at age 14 or 15, 33 percent had arranged marriages, compared to 18 percent of girls who married at age 16 or 17 , and 13 percent of girls who married at 18 or 19 . A considerable number of married adolescents and young women are in polygamous unions, with nearly one in five married girls in polygamous unions in Coast, Rift Valley and North Eastern Provinces. In addition, many of the girls who are currently in monogamous unions may eventually end up in polygamous unions.

The younger a girl is when she marries, the larger the age difference with her spouse. Girls who married at age 14 or 15 were, on average, 11 years younger than their spouse. Girls who married at 16 or 17 were 9 years younger, while those who married at 18 or 19 were 7 years younger. Age differences between spouses have tremendous implications for power and decision-making in the household, especially when a girl is still very young and her spouse is considerably older and more mature.

Married girls are significantly more likely to have children compared to unmarried girls, with only 12 percent of unmarried girls aged 15 to 24 being mothers, compared to 83 percent of married girls in the same age group. The earlier that one gets married, the earlier one gives birth. Median age at first birth was 16 for girls married at 14 or $15 ; 18$ for girls married at 16 or 17 ; and 19 for girls married at 18 or 19 . With early first births being the most risky, many girls are not prepared for pregnancy and do not receive adequate support, including medical attention, during the prenatal and perinatal period.

\section{Marriage and HIV Risk}

There is emerging evidence that married adolescent girls are at increased risk of HIV infection compared to their counterparts who are unmarried and sexually active. A recent study conducted in four African cities including Kisumu, utilized biomarker data. The study revealed that 33 percent of married girls are HIV+ compared to 22 percent of unmarried sexually active girls (Clark, 2004, Glynn et al, 2001). Once married, intercourse is much more frequent and condom use, virtually non-existent. A study by Clark (2004) demonstrates that the husbands of married adolescents in Kisumu are considerably older and much more likely to be HIV-infected compared to the boyfriends of unmarried girls. Married adolescent girls also have sex much more frequently than unmarried girls and are significantly less likely to use a condom than unmarried girls. Analysis revealed that the age and HIV profile of girls' husbands and sexual

\footnotetext{
${ }^{1}$ The statistics in this section are based on Population Council analysis of the 2003 Kenya DHS.
} 
frequency were risk factors that override risk related to the multiple partnerships of some unmarried girls. For girls in traditional rural settings, marriage or engagement often marks the beginning of their sexual life and, indeed, of HIV risk. Likewise, parents who wrongfully assume that marriage protects them from HIV frequently arrange girls' marriages. Traditionally, young brides move to their husbands' homes where they have low status, are relatively isolated, and lack power in decision-making, including sexual decision-making.

Among girls aged 15 to 24, those who are married are significantly less likely to know how to prevent HIV infection compared to their unmarried sexually active counterparts. When compared to unmarried girls, married girls are significantly less likely to have heard HIV messages on the radio or through newspapers, and less likely to have heard about VCT or know where to get it.

\section{Justification for a Married Adolescent Program}

Though considerable investment has been made in research and programs for adolescents, most of those efforts have been directed toward unmarried youth and not the sizeable proportion of young women who are married during adolescence. Married adolescent girls may be at heightened reproductive risk compared to unmarried girls, yet little attention has been given to this group. Married adolescents are more likely to be pregnant during adolescence, an experience that represents increased risk of maternal morbidity and mortality. They are also less likely to access healthcare during pregnancy or delivery compared to girls who give birth later. They may be at increased risk of HIV infection because of their partners' profiles and their frequency of unprotected intercourse. At the same time, they are less likely to have been reached with HIV information than their unmarried, sexually active counterparts.

Information on and programmatic experience with married adolescent girls is limited. Few studies have focused on how adolescents make the transition to marriage, what their perceptions of marriage are, and how their lives change. Likewise, there is little experience in programming for this group, which may be more vulnerable and at heightened risk of adverse reproductive health outcomes.

This project will expand on knowledge about married adolescents in Kenya, a large, neglected sub-group of young people. It will highlight their vulnerabilities and give program planners important lessons on how to reach this largely neglected group. The project will test three interventions that seek to assist married adolescents or adolescent girls just prior to marriage to protect their health. The lessons learned in the project will assist HIV programmers to mount prevention efforts among a large and, primarily, neglected risk group. Lessons will also highlight the vulnerability and risk of married adolescent girls in giving youth serving organizations guidelines on how to work with this group.

The project described in this report took place in two districts within Nyanza Province, Rachuonyo and Homa Bay. Nyanza Province has the highest rates of HIV infection in Kenya, with considerable gender imbalances. Nyanza has an overall HIV prevalence of 15 percent, followed by Nairobi with 10 percent. Eighteen percent of women, compared to 12 percent of men in Nyanza, are HIV infected. Seven percent of girls aged 15 to 19 compared to 0.7 percent of boys of the same age group in Nyanza are infected while 26 percent of girls aged 20 to 24 compared to six percent of boys of the same age group are infected. The national infection rate is seven percent (KDHS 2003). 


\section{OBJECTIVES}

The general objective of the project was to inform policy makers and program managers on experiences of reaching out to married adolescents with information on HIV risks. The specific objectives were:

1. To design and implement educational strategies to raise awareness of the risks of HIV and early marriage;

2. To promote voluntary counseling and testing for couples through an innovative coupon system; and,

3. To support and empower newly married girls through community married girls' clubs.

This report describes: (a) the formative research and pilot program implementation in Rachuonyo District, and (b) the implementation of a baseline survey and program scale-up in Homa Bay District. These activities precede a future follow-up survey and final evaluation in Homa Bay District which is planned for 2008-2009 under USAID funding.

\section{FORMATIVE RESEARCH AND INTERVENTION DEVELOPMENT}

Given the innovative nature of the project, a staged approach was used for intervention design and program evaluation. Initial formative research was undertaken in order to inform and refine intervention activities. Formative research was undertaken in Rachuonyo District in August 2005 to inform and refine intervention activities. Thirty-three in-depth interviews were conducted (with eight married adolescent girls, eight husbands of adolescent girls and 17 parents in law), exploring their views of marriage and their experiences in the transition to marriage.

The formative research conducted in Rachuonyo indicated that early marriage is common among adolescents who have lost their parents, mostly as a result of HIV/AIDS, or because of family poverty. Subsequently, a program planning meeting was jointly held by all partners to use research findings in message and intervention development.

\section{Pilot Phase in Rachuonyo}

The first phase of the project was used to pilot test the approach in Rachuonyo District, with emphasis placed on message development, training, and monitoring of program perception. The first year's implementation demonstrated that the program was feasible, appropriate and well received by adolescents, parents and other counterparts.

\section{Intervention Development}

Population Council supported PATH to conduct ARH (Adolescent Reproductive Health) training for mentors, theatre troupes, church leaders and VCT counselors. The trainings were conducted at the beginning of the project and additional refresher trainings were held in May 2007. PATH facilitated the training using an adolescent reproductive health and life skills manual ("Tuko Pamoja”) developed by FRONTIERS and PATH. Additional training particularly on ARH was provided by Family Health Options Kenya (FHOK) and Ministry of Health facilitators. 
Population Council facilitated training in data collection and record keeping. The training equipped participants with skills to provide information on reproductive health, HIV/AIDS, STIs, mobilization techniques, basic counseling, group formation processes, income generation activities and record keeping. Two refresher trainings were conducted and these concentrated mainly on HIV and AIDS.

Based on formative research, three strategies to address HIV risk among married adolescent girls were developed and implemented:

1. An education campaign to sensitize communities, families and young people that marriage is not protective of HIV and on the benefits of premarital VCT. Educational strategies included radio spots, drama groups, and religious leaders;

2. Promotion of premarital VCT services for couples including referral and linkage with existing services and subsidies for associated travel costs from rural areas into towns, where services are generally located;

3. Support groups for married girls and families using this innovative mentoring approach.

\section{Educational campaigns using radio, drama, and religious leaders}

Population Council provided funding to PATH to conduct educational campaigns through radio and drama. The Council also awarded Kendu Adventist Hospital funding to conduct educational campaigns through religious leaders. Formative research undertaken by the Council informed development radio messages by the Council and PATH that were pretested in focus group discussions over a period of four days with married and unmarried adolescent girls, adolescent boys aged 15 to 24 years, adult men and women as well as opinion leaders and other stakeholders in the two districts. The spots were selected on the basis of married adolescents and other community members' high rankings in terms of ease of comprehension, relevance, clarity, language acceptability, attractiveness and call for action.

Radio Ramogi, established in 2003, and Lake Victoria FM, established in 2006, broadcast in the local Luo language, Dholuo. The two stations have varied programs with numerous musical shows, news broadcasts, funeral announcements and greetings programs which are very popular with the community. The stations also have talk shows where people are invited to discuss current issues and interact with experts. One notable talk show is "Duond Mine" (Women's Voice) a program dedicated to women and their problems on Radio Ramogi and "Oru Nyakanam" (a breakfast show) on Lake Victoria FM. These stations broadcast for 24 hours compared to Kenya Broadcasting Corporation (KBC), which only broadcasts in Dholuo for a total of three hours every day. With broadcasts in the Luo language, the stations are extremely accessible to the local population. The two radio stations were selected after a listenership assessment conducted by PATH and the Steadman Group indicated that they had the widest reach in the targeted community, reaching approximately 350,000 to 500,000 people.

Radio Ramogi and Lake Victoria FM broadcast the seven radio spots developed and pretested by PATH. The messages inculcate cultural traditional sayings, and are rich in proverbs and popular songs, thus making the community relate to them. The radio spots were used to deliver different 
thirty second messages targeting radio audiences. Radio spots encouraged listeners, particularly girls, to wait for the right time to marry, to know their own and their partners' sero-status, and to use condoms within marriage. For maximum effect, the spots went on air during hours that most young people preferred listening to the radio. These included during the breakfast shows, a few minutes before or after prime time news, and during death and funeral announcements.

Since January 2006, over 250 radio messages have been aired on Radio Ramogi and Lake Victoria FM. A listener survey conducted by PATH indicated that many members have heard the radio spots and like them. Mentors and theatre troupes contributed to the wide listenership by asking community members to listen in and by reinforcing the messages community members had heard over the radio, thus increasing the credibility of the information. Community members reported they were privileged to be associated with a program that promotes the reproductive health of the married adolescents.

PATH has extensive experience in undertaking community-based "magnet theatre" as well as working with local groups in Rachuonyo and Homa Bay Districts. Their focus on youth reproductive health, IEC materials development and expertise in participatory theatre made them an appropriate partner to coordinate community based theatre activities at district level. Magnet Theatre is a drama technique developed by PATH. It employs episodic dramas that are participatory, engaging the audience in problem solving and conflict resolution. Magnet Theatre was used to increase HIV and AIDS knowledge, generate interest in couples' VCT, delay early marriage, reduce the number of sexual partners and create confidence in condom use. Theatre groups educated the audience on communication in marriage, cross generational sex, faithfulness, abstinence, the use of condoms, risks of early marriage, a range of RH issues and marital HIV transmission. The drama troupes also referred those willing to be tested by giving out coupons. Drama troupes performed at the same venue each week attempting to draw the same audience the same way that a television series seeks to retain loyal viewers over time. Formative research results were used to develop appropriate messages. Community drama troupes were involved to ensure that the messages developed were relevant and culturally appropriate to the audience. Magnet Theatre drew performers from local theatre groups that performed at predetermined venues within the community, including open spaces, market centers or under a tree. Magnet Theatre performers created several dilemma points where the audiences were challenged to provide a solution or choose the best decision. The storyline proceeded on the basis of that behavior.

Kendu Adventist Hospital is linked to the Seventh Day Adventist Church which has a huge following in Southern Nyanza. The Church has numerous HIV-related activities throughout Rachuonyo and Homa Bay Districts. The program works with 26 community opinion leaders, has built the capacity of 25 "trainers of trainers", 115 community health workers, and 882 caregivers in 8 locations. The Kendu Adventist Hospital runs a home-based care program, has a VCT center at the Adventist hospital and works with women group leaders and fishing communities to reach people with HIV/AIDs information. The hospital's current program includes outreach to youth in schools and through churches of other denominations and targets couples with family life education. The hospital works collaboratively with many other groups including Christian Children's Fund (CCF), MORCAO, Adventist Relief Agency (ADRA), and churches of all denominations. 
Population Council worked with the Kendu Adventist Hospital to conduct advocacy. The advocacy intervention reached out to the community members on behavior change as well as the risk of early marriage. Advocacy was conducted by trained church and civic leaders. Religious leaders are important sources of credible information and for setting and re-enforcing societal norms. During the initial stages, the dominant churches in each locality recruited well known influential members of the community. Selection criteria for candidates included the belief that child marriage is abhorrent, literacy and expressed enthusiasm for the project. A total of 60 religious leaders were recruited and trained on various reproductive health issues. Religious leaders also make referrals for VCT and use their expertise to relate child marriage to biblical or teachings of the Quran. Religious leaders implemented their action plans and agreed upon advocacy messages related to early marriage, HIV and reproductive health twice every month. Church leaders held two to three sermons every month and a total of 12 monthly review meetings.

\section{Promotion of VCT services}

VCT services were designed to address manageable barriers to VCT use including the costs of travel to the VCT sites. Initial campaigns through radio spots, by theatre troupes, church leaders and mentors created awareness of VCT and drew attention to the attributes and benefits of the counseling offered, built community confidence in the quality of VCT services and addressed issues of access and affordability.

VCT services reinforced the ideas that many individuals, and particularly married adolescent girls, are vulnerable and susceptible to HIV infection; that sexually active people are most at risk of contracting HIV/AIDS; that getting infected affects plans for the future and the ability to provide family support. Encouragement to seek VCT services included looking at the implications of the sexual past of partners, particularly older husbands of married adolescent girls as well as unmarried girls' boyfriends. VCT services also helped to manage the fear of HIV positive test outcomes, one of the biggest barriers to HIV testing.

Formative research results showed that VCT sites were not easily accessible to clients. Building on the Population Council's successful coupon system for adolescents (developed in Nyeri and subsequently expanded through the 'Friends of Youth' model) to refer youth for services, a similar coupon system was introduced for transport subsidies, effectively reducing the cost of transport as a barrier to the access of VCT services that are free in Kenya.

The project intended to use all 24 registered VCT services within Rachuonyo and Homa Bay Districts. At the time the project started, however, three VCT centers in Rachuoyo had closed. In Homa Bay, ten VCT centers were identified but only seven agreed to participate in the project. Ultimately, 14 registered VCT sites actively participated in the project. Three public hospitals in Homa Bay, including the District Hospital, declined to participate because of the District Health Management Team's (DHMT) reluctance to allow staff to manage coupon-related finances.

\section{Mentorship for married girls}

Population Council and PATH worked with the Kendu Adventist Hospital in the mentoring intervention. Kendu Adventist Hospital, with the support of trained church leaders, identified mentors to mobilize and conduct mentoring activities for married adolescent girls within the 
project sites. Female mentors, who were well known, respected in the community and literate, were selected. Mentors were old enough to exert influence over adults as well as young people. Mentors received training on a number of topics including HIV/AIDS, sexually transmitted infections, prevention of mother-to-child transmission (PMTCT) of HIV, spousal communication, reproductive health, family planning and group-facilitation skills. In order to create an enabling environment for married adolescents, mentors involved husbands and parents/in-laws in such clubs. Before mobilizing girls' groups a simple community diagnosis format was devised that mentors used to identify girls who were eligible for the girls' groups.

\section{RESEARCH METHODS}

Building on the successes in Rachuonyo, intervention strategies were scaled up and replicated in Homa Bay District, geographically adjacent to Rachuonyo, in 2007. Homa Bay has a big fishing population, largely dominated by men. Other economic activities include farming and livestock rearing. This second phase included expansion of the project as well as mechanisms to evaluate the project's impact.

Two methods were used to evaluate the reach and effectiveness of the interventions. Service data including the numbers of people reached by the theatre, advocacy, and mentorship programs were recorded in both Rachuonyo and Homa Bay districts during the pilot and scale-up phase. While this simple enumeration of individuals reached has its limitations in terms of interpretation, this was the type of coverage indicator required by PEPFAR. To evaluate the intervention to reach vulnerable married adolescent girls in Nyanza, a baseline survey was conducted in Homa Bay as part of the scale up activities.

\section{Monitoring and Management Information System}

A management information system was collaboratively developed by partners to monitor project progress and achievement of outputs. Registers were used to record the numbers and profiles of people reached by various service providers. The facilitators for the married girls' groups kept records of all those reached during group meetings as well as the content of the group meetings. The coupon system is used to monitor those who access VCT.

Population Council, PATH and Kendu Adventist Hospital collaboratively developed record keeping forms for all of the interventions' major activities, with forms specific for each activity and person responsible for recording the information. Mentors, theatre group members, church leaders and VCT counselors responsible for recording information were all trained in completing the registers correctly. Additionally, the project adopted the national Voluntary Counseling and HIV Testing form. Population Council field coordinators facilitated the collection of completed registers that were sent to the Population Council office in Nairobi for data processing into an electronic database created for the project. Community-based service providers as well as clinic based providers kept the married adolescents client register. 


\section{Baseline Quantitative Survey}

Homa Bay District in southern Nyanza has an estimated population of 340,000. Homa Bay borders Lake Victoria and the predominant ethnic group is the Luo, a traditionally fishing and non-circumcising community. In Luo culture, marriage is exogamous, with women moving outside their home area to marry. Girls often marry through arrangement by a go-between called 'jagam'. Homa Bay has one of the highest rates of HIV infection in Kenya, estimated by AMREF at about 28-30 percent. Homa Bay District is also one of the poorest of the 12 districts in Nyanza Province and has about 40,000 orphans with 16,000 having lost both parents. Child marriage is more likely to occur among individuals of low economic status, living in a rural area and with limited education (Bledsoe and Cohen, 1993, AGI, 1998, Mensch, Bruce and Greene, 1998).

The study explored the experience of marriage, including violence and the perception of HIV risk. The study sought to expand our understanding of the experience of marriage in a high HIV prevalence setting. The study was conducted in the three divisions of Homa Bay District in Nyanza Province (Rangwe, Asego, Ndhiwa). A probability sample was used to randomly select households in enumeration areas identified with the assistance of the Central Bureau of Statistics. Interviewers visited each household to collect basic demographic information from all household members. This information was entered into a computer software program and independent subsamples were randomly selected based on the following eligibility criteria: girls between the ages of 10 and 24; boys between the ages of 10 and 24. If a household had more than one eligible adolescent, a Kish grid was used to randomly select one adolescent.

Structured questionnaires were developed for interviewing adolescents. They were translated into Dholou and back-translated to English to ensure accuracy. Questionnaire items were primarily closed-ended with some open-ended questions on issues for which there was limited prior information. The questionnaire covered topics such as demographic information, socioeconomic status, marriage, attitudes and expectations about the future for adolescents, decision-making, reproductive health knowledge and practice, childbearing, exposure to radio spots, questions about substance use and sexual experience, migration and fostering, time use, and social networks and mobility.

In addition, there were selected open-ended questions from which quotes were derived. These included questions on descriptions of harassment in the work place, insecurity, the best age to marry and the reasons, discussion on VCT and gender violence among others. Direct quotes from open-ended questions were translated into English and typed into a Microsoft Word file. These responses were analyzed qualitatively, with issues and patterns identified in the responses and illustrative quotes presented to reflect the most common patterns.

Interviewers with previous research experience and a minimum of a secondary education were recruited locally and attended two five-day trainings. The first training focused on household listing while the second training incorporated a review of each item on the questionnaires, general interview techniques and mock-interviews. Interviewers made up to three attempts to locate and interview each respondent. Face-to-face interviews were conducted by same-gender interviewers at respondents' homes, schools, or other convenient locations. Before each interview, informed consent was obtained from all respondents and parents of respondents who were minors along with the assent of these respondents. 


\section{RESULTS}

\section{A. Service Statistics}

Community based service providers as well as clinic-based providers kept a married adolescents client register. Through this register, the project was able to track service delivery outputs and project reach.

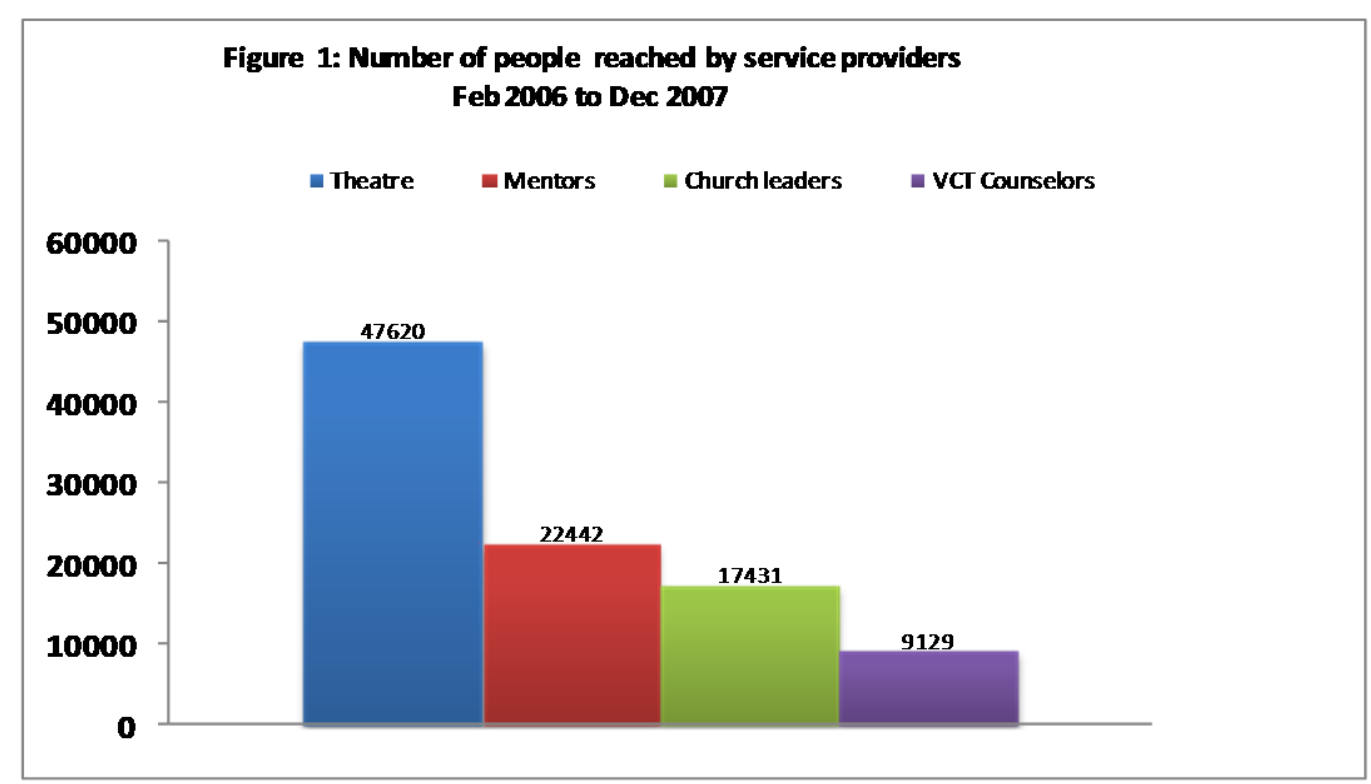

Between February 2006 and December 2007, the project reached 65,091 new clients through 96,622 client contacts. Theatre troupes had the highest reach with over 47,600 contacts. Most community members reached were aged between 15 and 19 years. Among those reached, 26 percent were boys and 49 percent were girls. In addition, the project reached older adolescents: 23 percent of boys and nearly 22 percent of girls were aged between 20 and 24 years. Thirteen percent of the males reached and six percent of the females were adults aged forty and above. Seventy-one percent of males and females were reached through group contact, nearly 10 percent through individual contact, and 19 percent through couples' contact.

Most community members reached were out of school. Fully 69 percent of males and 74 percent of females were out of school compared to 30 percent of males and 24 percent of females who were still in school. About 2.5 percent of the community members reached had no education, 45 percent had primary education, 42 percent had secondary education and 6 percent had postsecondary education. Fifty-five percent of the males reached were married compared to 72 percent of women.
Table 1: Percent of people reached by age group (Feb 2006 to Dec 2007)

\begin{tabular}{|l|c|c|}
\hline \multirow{2}{*}{ Age category } & \multicolumn{2}{|c|}{ Percent } \\
\cline { 2 - 3 } & Male (n=37,987) & Female (n=54,861) \\
\hline $10-14$ & 3.9 & 3.9 \\
\hline $15-19$ & 26.2 & 49.1 \\
\hline $20-24$ & 23.2 & 21.6 \\
\hline $25-29$ & 17.2 & 10.1 \\
\hline $30-34$ & 10.7 & 5.9 \\
\hline $35-39$ & 6.5 & 3.4 \\
\hline $40+$ & 12.6 & 6.0 \\
\hline
\end{tabular}




\section{Theatre Outreach Contacts}

Fourteen theatre groups facilitated Magnet Theatre performances reaching over 20,500 new male clients, 17,300 new female clients, 5,100 continuing male clients and nearly 4,600 continuing female clients. Theatre troupes employed several techniques to reach their audiences. They shared experiences with over 8,500 community members, reached over 1,700 community members through expert speakers, provided skills demonstrations including condom demonstrations and saying no to unwanted sex as well as support for VCT to over 4,800 people; discussed reproductive health one on one with over 8,400 people; and invited over 2,400 people in the target audience to make their own creative simulations.

Drama content included HIV information reaching over 27,850 people; STI information reaching over 19,000 people; VCT reaching over 35,900 people; ARV reaching over 6,800 people; stigma and discrimination reaching over 9,000 people; information on HIV/AIDS care and treatment reaching over 8,500 people; faithfulness reaching over 21,000 people; abstinence reaching over 18,800 people; marital risk reaching over 9,700 people; messages on cross generational sex reaching over 9,100 people; family planning reaching over 3,300 people; condom use reaching over 18,400 people; messages on gender violence, sexual coercion and rape reaching over 5,000 people; safe motherhood reaching over 2,000 people and communication in marriage reaching over 6,400 people. Theatre troupes referred over 16,400 people for VCT. Other referrals included over 2,300 people for ARV; over 3,100 people for post-test clubs; over 2,400 people for family planning and over 1,500 people for STI treatment.

\section{Religious Advocacy Contacts}

Religious leaders were highly effective in reaching thousands of individuals on a range of topics (see Table 2). In addition, religious leaders made over 1,150 referrals for VCT; 99 referrals for ARV; 67 referrals to posttest clubs; 139 for family planning and 150 for STI treatment. A mix of interpersonal and electronic communication media delivered early marriage and VCT messages effectively. Electronic media was used to increase community awareness of VCT attributes and benefits while interpersonal communication channels enabled referrals, reinforced electronic media messages and linked clients and services.

\begin{tabular}{|l|c|}
\hline \multicolumn{2}{|c|}{$\begin{array}{c}\text { Table 2: Topics covered by church leaders and } \\
\text { numbers of individuals reached (Feb 2006 to Feb 2008) }\end{array}$} \\
\hline \multicolumn{1}{|c|}{ Topic } & Number \\
\hline Faithfulness & 8,184 \\
\hline HIV & 6,774 \\
\hline VCT & 6,098 \\
\hline Abstinence & 4,175 \\
\hline Stigma \& discrimination & 4,096 \\
\hline Care support \& treatment & 4,079 \\
\hline STls & 4,043 \\
\hline Gender violence & 3,990 \\
\hline Condom use & 3,769 \\
\hline Marital risk & 3,177 \\
\hline Cross generational sex & 2,033 \\
\hline ARV & 1,814 \\
\hline
\end{tabular}




\section{VCT Contacts (Outreach and Facility)}

Although VCT counselors are clinic-based service providers, they often provided information and services outside clinical settings. VCT counselors reported seeing, over 8,400 new clients through more than 9,100 contacts. There were over 630 return clients, mostly polygamous husbands who wanted to be tested at different times with each wife.

Counselors discussed HIV with over 9,000 people; STIs with over 3,300 people; VCT with almost 5,000 people; ARV with 3,600 people; marital risk with over 2,400 people; and condom use with over 5,600 people. The VCT counselors referred over 3,900 clients for testing; about 2,000 for ARV; 2,600 to post-test clubs; over 900 for STI treatment and over 1,500 for family planning.

The National Voluntary Counseling and HIV Testing data indicate that 3,580 individuals (1,765 men and 1,815 women) visited the facilities. Of these individuals, 49 percent were married in monogamous unions, 17 percent were single, 12 percent were married in polygamous unions and 10 percent were in a steady relationship. Two hundred and forty-five were seen as individuals, over 3,200 were seen as couples, and 51 as polygamous groups. Nearly all clients had gone for the full VCT service, including over 170 pregnant women. Most clients (91 percent) wanted to know their status to plan for the future. Nearly nine percent reported visiting the VCT clinic because they or their partners had participated in risky behavior; 10 percent because they felt unwell and suspected they may have been infected and four percent sought VCT services after the window period.

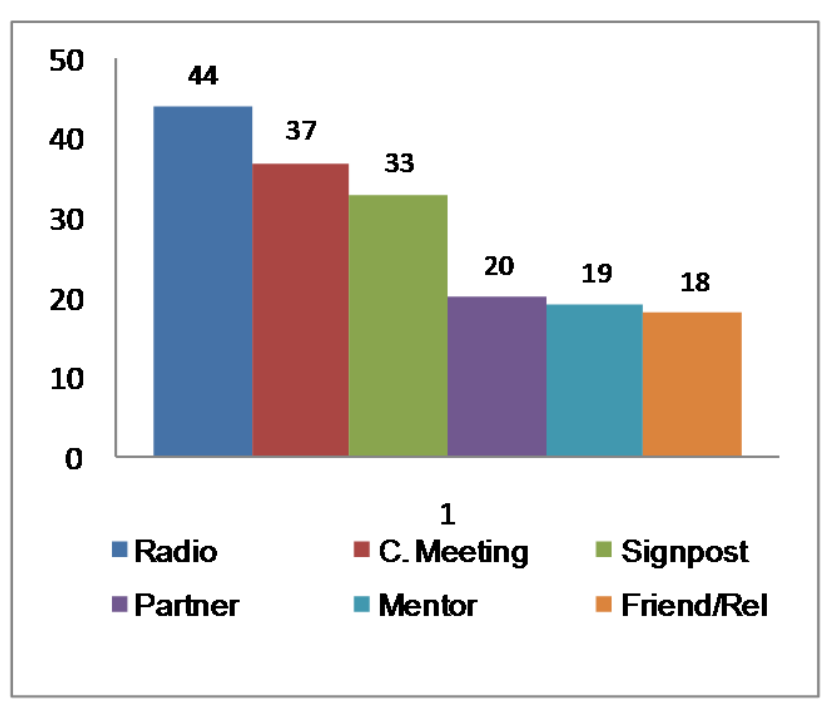

Most clients (44 percent) learnt about the VCT service from the radio, most probably Radio Ramogi and Lake Victoria FM. Thirty-seven percent reported they learnt about the service from community meetings convened by the Magnet Theatre troupes and 19 percent from girls' mentors.

Service providers reported that community members referred for VCT often come back to them for guidance when faced with a positive result expressing the need by those accessing VCT services for subsidies on transport and service costs for post-test services including CD4 counts and ART.

\section{Married Girls Reached by Mentorship Program}

A total of 90 mentors worked with girls' clubs in the two districts and out of these about 80 were active. Mentors in Rachuonyo each held between 24 and 48 meetings with the young women's clubs in the past year and on average mentored about 1,900 adolescent married women. In Homa Bay, mentors have each recruited between 18 and 35 members. 
The mentors' meetings discussed HIV with information reaching over 7,600 people; STIs reaching over 5,300 people; VCT reaching over 6,800 people; ARV reaching over 2,500 people; stigma and discrimination reaching over 3,700 people; HIV/AIDS care support and treatment reaching over 4,600 people; gender violence, coercion and rape reaching over 3,000 people; condom use reaching over 4,100 people and income generating activities. Other activities undertaken by the various clubs included sports, drama and music. Mentors have referred over 1,900 community members for VCT; nearly 75 people for ARV and nearly 330 for STI treatment.

\section{B. Baseline Survey}

A total of 2,838 adolescents aged 10 to 24 were interviewed. More girls than boys were interviewed, with the greater number of girls likely a reflection of the larger female population in the study areas as well as the availability of girls at home. Boys, particularly older boys, have been traditionally harder to locate for community surveys in most countries. In all, 1,947 girls were interviewed compared to 891 boys, a ratio of 2.2 girls for every boy. In addition, girls were significantly more likely to be out of school compared to boys, with 39 percent of the female sample not attending school, compared to 23 percent of boys. At the same time, the female sample was slightly older with a median age of 16 , than the male sample (median age $=15$ ). Adolescent girls were significantly more likely to be married than boys. Thirty-four percent of girls were ever-married compared to six percent of boys.

Among adolescents who lived with their parents, nearly $48 \%$ had low household level socioeconomic status, 50 percent had medium socio-economic status and only two percent had high socio-economic status. Among those not living with their parents, nearly 88 percent had low socio-economic status and only 12 percent had medium socio-economic status.

Thirty-nine percent of the girls had lost their fathers and 18 percent their mothers. Overall, 12 percent of the respondents were double orphaned and about a third ( 32 percent) had lost one parent. Most adolescents whose parents had died reported their parents died when they were very young. Seventy-seven percent reported their fathers died when they were less than 15 years of age and 66 percent reported their mothers died when they were under 15 years. There were no significant differences in orphan status between boys and girls. Thirteen percent of girls were double orphans compared to 12 percent of boys. Fifty-six percent of adolescents had both parents alive.

Thirty-four percent of the girls surveyed had ever been married, with median age at first marriage being 18. Thirteen percent of married adolescent girls were beaten by their husbands in the last three months, and 29 percent had been forced to have sex against their will. Thirty-one percent of married adolescent girls fear that their spouse will infect them with HIV/AIDS. Those who feared marital HIV infection were significantly more likely to have spouses who drink (18\% versus $10 \%)$, who beat them (20\% versus $10 \%)$, who forced them to have sex $(50 \%$ versus $20 \%)$, and who were unfaithful (18.5\% versus $3 \%$ ) than girls who did not fear HIV infection. 
Analysis of open-ended answers revealed the girls' vulnerability to domestic violence:

"We went to the market and delayed coming back. When we finally came back, it ended up in him beating me" Married adolescent girl, age 16, married at age 15 to a 21 year old man, with 6 years of education.

"He hit me when I insisted on not having sex without using a condom, since he had been away for two months and I did not trust him" Married adolescent, age 19, married at age 18 , with 7 years of education.

A considerable number of girls described getting married after their parents died, with more double orphans marrying earlier than young women with two living parents. Girls described having no one to support them, and so entered marriage for support:

"My parents were no longer alive so my aunt suggested that I should get married to one of the extended family members, because she could no longer take care of me" Married adolescent girl, age 17, married at age 15 to 30 year old man, with 7 years of education.

"My sister was married but she did not give birth to any child. So my sister, her husband and my father forced me to get married to her husband" Married adolescent girl, age 22, married at age 16 to 19 year old man, with 5 years of education.

\section{Dissemination}

Dissemination of project progress data has been conducted through stakeholder quarterly meetings. A community dissemination of the formative research findings was conducted. A national dissemination meeting will be held in Nairobi later in 2008. Additional dissemination will be conducted through papers for publication and briefs for policy makers.

\section{DISCUSSION}

The strong technical support and leadership provided by partners led to the successful implementation of most project activities. The partnership has enabled scarce resources to be shared, and has ensured that the comparative advantages of each partner has been effectively utilized. Benefits included access to staff, counterparts and sites the project would not have otherwise reached; good ideas, knowledge and skills and practical support. The theatre groups, the coupon system, mentors and religious leaders as well as the radio spots ensured the project was well known in the community. A large segment of the local population (nearly 100,000 thousand individuals) was reached, with many community members also participating in project activities.

Theatre activities have immensely contributed to the demystification of HIV and VCT. Theatre groups' have created rapport with community members who have been involved in their skits and have participated in discussing HIV and other healthy behaviors. In addition, character magnification has enabled community members to give testimonials as a behavior change communication strategy. People who had changed behaviors after listening to characters voluntarily gave testimony of their lives before and after visiting VCT sites. Community 
members reported requesting for referral coupons from theatre group members, an indication that stigma is reducing and people feel freer about going for VCT. Additionally, community members felt theatre troupes have effectively persuaded them to go for couples testing. Nearly all theatre group members have been tested and know their HIV status.

The mentorship program succeeded in reaching married girls who would otherwise have remained isolated in their households. This success was also dependent on additionally inviting relatives of group members, including husbands and parents-in-law, to discuss issues that arose during group meetings. Their participation has promoted the program and reduced anxiety among husbands of married adolescents. Mentors worked in partnership with religious leaders to recruit young married adolescent girls into clubs and facilitate discussions.

The strategies that were implemented both respected and challenged cultural norms of early marriage, restrictions on public discussion of sex and sexuality and condoms or accompanying partners to health facilities, and acknowledged realities which are frequently denied in mainstream culture. As a result, many couples went jointly for VCT services and were jointly tested. Community members publicly discussed condoms, witnessed condom demonstrations and openly discussed HIV and VCT.

The project helped health and development workers to understand that vulnerability to HIV both motivates and focuses responses. Gender, sexuality and sexual health are known to be significant determinants of vulnerability to HIV. Equally, attention to these issues is a key pathway beyond awareness-raising. NGOs and Faith-based Organizations that were otherwise prone to work with the general public to "create awareness" worked in a focused way to reach couples with VCT messages and encouraged action. As a result, community members viewed early marriage and marital VCT with different lenses.

Demand for VCT is created when barriers to access are reduced. VCT is an important component of behavior change that facilitates early referral for care. For couples testing negative, VCT is a strategic tool to encourage long-term faithful relationships. For couples testing positive, VCT is equally a powerful tool to encourage health seeking behavior that prolongs life and maintains social and economic productivity.

The community intervention using the coupon referral system has assisted in convergence with the public health system, and has gone some way to promote a sense of shared ownership of the program between the Ministry of Health, NGOs and the community. More equitable distribution of responsibilities and commitments between the government, NGOs and the community will further enhance shared ownership, as the government currently plays a peripheral role.

\section{Programmatic recommendations}

- Service providers reported that community members referred for VCT often come back to them for support when faced with a positive result expressing the need for subsidy on transport and service costs for post-test services including CD4 counts and ART. The project should continue to provide the transport subsidy as well as provide service subsidies through the coupon system, for many people to access post test services. 
- Support from community leaders is an important factor that has contributed to the successful implementation of the project. Additional community leaders, other than religious and civic leaders, need to be identified to form a critical mass of leaders advocating for couples VCT and against early marriage among adolescent girls.

- Volunteer involvement, including that of married youth and additional community mentors, should be expanded and strengthened. Volunteers including mentors, religious leaders and theatre troupes should begin to assume most of the social support responsibilities including the mentoring of post-test club members. 


\section{REFERENCES}

Glynn JR, Caraël M, Auvert B, Kahindo M, Chege J, Musonda R, et al. 2001. Why do young women have a much higher prevalence of HIV than young men? A study in Kisumu, Kenya and Ndola, Zambia AIDS.15 (suppl 4): S51-60.

Alan Guttmacher Institute (AGI). Into a New World: Young Women's Sexual and Reproductive Lives. New York: Alan Guttmacher Institute, 1998.

Amref:http://www.amref.org/docs/HIV_AIDS\%20orphans\%20Homabay\%20Project\%20Summa ry.pdf

Bledsoe C, Cohen B. Social Dynamics of Adolescent Fertility in sub-Saharan Africa. Washington DC: National Academy Press, 1993.

Clark S. 2004. Early marriage and HIV risk in sub-Saharan Africa, Studies in Family Planning, December.

Mensch B, Bruce J, Greene M. The Uncharted Passage: Girls' Adolescence in the Developing World. New York: Population Council, 1998.

National Council for Population and Development (NCPD), Central Bureau of Statistics, Macro International. Kenya Demographic and Health Survey, 1998, Calverton Maryland, 1999.

McCauley AP, Salter C, Kiragu K, Senderowitz J. Meeting the needs of young adults. Popul Rep J 1995. 41:1-43. 